\title{
Karakteristik dan Distribusi Spasial Habitat Positif Larva Nyamuk Anopheles spp. Berdasarkan Curah Hujan
}

\section{Characteristics and Spatial Distribution of Anopheles spp. Mosquito Larval Habitats Based on Rainfall}

\author{
Noper Tulak $^{1 *}$, Handoko², Rini Hidayati², Upik Kesumawati Hadi ${ }^{3}$, Lukman Hakim ${ }^{4}$ \\ ${ }^{1}$ Program Studi Teknik Geofisika Jurusan Fisika, FMIPA, Universitas Cenderawasih \\ ${ }^{2}$ Departemen Geofisika dan Meteorologi, FMIPA, Institut Pertanian Bogor \\ ${ }^{3}$ Bagian Parasitologi dan Entomologi Kesehatan, Departemen Ilmu Penyakit Hewan dan \\ Kesehatan Masyarakat Veteriner, FKH, Institut Pertanian Bogor \\ ${ }^{4}$ Pengendalian Penyakit dan Penyehatan Lingkungan, Kementerian Kesehatan RI \\ ('noper.tulak@gmail.com)
}

\begin{abstract}
ABSTRAK
Penyakit malaria masih menjadi masalah kesehatan masyarakat di Kota Jayapura. Penyakit ini tersebar pada semua wilayah dengan jumlah kasus yang bervariasi. Peningkatan penularan penyakit malaria dipengaruhi oleh kondisi lokal, termasuk curah hujan, karakteristik habitat dan sebaran habitat larva. Tujuan penelitian ini untuk mengetahui karakteristik habitat dan pengaruh curah hujan terhadap sebaran habitat positif larva nyamuk Anopheles spp. di Distrik Heram Kota Jayapura. Metode yang digunakan merupakan observasi lapangan dengan pendekatan analisis deskriptif dan statistik. Hasil penelitian menunjukkan bahwa ada 6 jenis habitat perkembangbiakan nyamuk Anopheles spp. di Distrik Heram, yaitu kobakan, kubangan, parit, kolam, kali dan bekas tapak ban. Habitat tersebut ditemukan di Kelurahan Waena dan Yabansai. Luas habitat larva berkisar antar 0.04-28 $\mathrm{m}^{2}$, kedalaman air 5-115 cm, suhu air 26.7-33.7 OC dan $\mathrm{pH}$ air 6.7-7.7. Sebaran habitat positif larva signifikan dipengaruhi oleh curah hujan yaitu kubangan ( $\mathrm{p}=0.000 ; \mathrm{r}=0.69)$, kobakan $(\mathrm{p}=0.000 ; \mathrm{r}=0.87)$, parit $(\mathrm{p}=0,000 ; \mathrm{r}=0.57)$, bekas tapak ban $(\mathrm{p}=0.047 ; \mathrm{r}=0.34)$, kolam $(\mathrm{p}=0.000, \mathrm{r}=0.57)$ dan kali $(\mathrm{p}=0.007 ; \mathrm{r}=0.46)$ dengan koefisien determinan berkisar antara 0.11-0.77. Kesimpulan hasil penelitian menunjukkan bahwa curah hujan mempengaruhi sebaran habitat positif larva nyamuk Anopheles spp. di distrik Heram.
\end{abstract}

Kata kunci : Distribusi spasial, curah hujan, Anopheles spp.

\section{ABSTRACT}

Malaria is still a public health problem in Jayapura City. The disease is spread throughout the region with varying number of cases. Increased transmission of malaria is affected by local conditions, including rainfall, habitat characteristics and larval habitats distribution. The aims of study were to describe habitat characteristics and spatial distribution a habitat of positive of an Anopheles larvae spp based on rainfall in Heram District, Jayapura City. The method used is field observation with descriptive and statistical analysis approach. The results showed that there were 6 breeding site Anopheles Mosquito in Heram District, namely rain puddle, puddles, moats, ponds, rivers and former tire tread. The habitat was found in Waena and Yabansai village. The larval habitat area is 0.04-28 $\mathrm{m}^{2}$, water depth 5-115 cm, water temperature 26.7-3.7 and water $p H$ 6.7-7.7. A habitat of positive of an Anopheles larval spp were significantly affected by rainfall ie puddle $(p=0.000 ; r=0.69)$, rain puddle $(p=0.000 ; r=0.87)$, moats $(p=0.000 ; r=0.57)$, former tire tread $(p=0.047 ; r=0.34)$, pond $(p=0.000 ; r=0.57)$ and rivers ( $p=0.007 ; r=0.46$ ) with determinant coefficients ranging between 0.11-0.77. Conclusion of the results of the study showed that rainfall affected a habitat of positive of an Anopheles larval spp in Heram District Keywords : Spatial distribution, rainfall, Anopheles spp. 


\section{PENDAHULUAN}

Malaria merupakan penyakit infeksi yang disebabkan oleh parasit Plasmodium sp yang ditularkan oleh nyamuk Anopheles spp betina. Sampai saat ini malaria masih menjadi masalah kesehatan umum yang utama di seluruh dunia, terutama di negara-negara berkembang seperti Amerika Latin, Afrika sub-Sahara, Asia Selatan, sebagian Asia Timur, dan Asia Tenggara. Negara yang termasuk wilayah endemis malaria di Asia Tenggara, yaitu Bangladesh, Bhutan, India, Indonesia, Maldives, Myanmar, Nepal, Srilanka, dan Thailand. ${ }^{1}$ Hingga tahun 2015, insiden malaria di seluruh dunia diperkirakan mencapai 214 juta kasus yang telah menyebabkan kematian sekitar 438 ribu orang. ${ }^{2}$ Sementara di Indonesia, malaria juga masih merupakan masalah kesehatan masyarakat yang serius di beberapa wilayah. Angka kesakitan malaria di Indonesia sejak tahun 2013 hingga 2016 terus mengalami penurunan, yaitu 1.38 per 1000 penduduk pada tahun 2013 menjadi 0.77 per 1000 penduduk berisiko pada tahun $2016 .^{3}$ Walau demikian, angka kejadian malaria di wilayah bagian Timur Indonesia masih cukup tinggi khususnya di Propinsi Papua dan Papua Barat. Angka Annual Paracite Incidence (API) tahun 2016 menunjukkan bahwa Propinsi Papua memiliki API tertinggi sebesar 39.93 per 1000 penduduk disusul Papua Barat sebesar 10.20 per 1000 penduduk.

Trend kejadian malaria di Propinsi Papua selama periode tahun 2012-2016 berfluktuasi dari waktu ke waktu, yakni 60.56 per 1000 penduduk pada tahun 2012 menjadi 42.65 per 1000 penduduk pada tahun 2013. Kemudian mengalami penurunan yang signifikan pada tahun 2014 menjadi 29.57 per 1000 penduduk. Namun, dua tahun berikutnya mengalami peningkatan kembali menjadi 31.93 per 1.000 penduduk pada tahun 2015 dan 39.93 per 1000 penduduk pada tahun 2016 . Berdasarkan data tersebut, penyakit malaria termasuk dalam kategori 10 besar penyakit yang ada di wilayah ini.

Kota Jayapura merupakan salah satu wilayah yang masih memiliki angka kejadian tinggi malaria di Papua. Angka kesakitan malaria di wilayah ini selalu berfluktuasi dari waktu ke waktu. Pada tahun 2010 jumlah kasus malaria yang teridentifikasi sebanyak 71.421 per 1000 penduduk kemudian mengalami sedikit penurunan pada tahun 2011 menjadi 70.11 per 1000 penduduk, tetapi dua tahun berikutnya kembali mengalami peningkatan menjadi 82.41 per 1000 penduduk pada tahun 2012 dan 85,32 per 1000 penduduk pada tahun 2013 . Selanjutnya mengalami penurunan pada tahun 2014 menjadi 54.92 per 1000 penduduk. ${ }^{4}$ Salah satu daerah di Kota Jayapura yang memiliki angka kejadian tinggi malaria adalah distrik Heram. Jumlah kasus positif malaria yang teridentifikasi di wilayah ini berfluktuasi, yaitu 2221 kasus pada tahun 2013 atau 52.27 per 1000 penduduk sedangkan pada tahun 2014 mengalami penurunan menjadi 1372 kasus atau 32.29 per 1000 penduduk. $^{4}$

Penularan penyakit malaria cenderung dipengaruhi oleh kondisi lokal diantaranya iklim dan ketersediaan habitat akuatik sebagai tempat perkembangbiakan nyamuk. Curah hujan merupakan salah satu faktor iklim yang paling dominan dalam penyebaran penyakit malaria karena dapat mempengaruhi jumlah habitat maupun kepadatan nyamuk anopheles pra dewasa. ${ }^{5}$ Besar kecilnya pengaruh hujan bergantung pada intensitas, jumlah curah hujan dan hari hujan serta karakteristik fisik habitat larva. Pada kondisi tertentu, curah hujan dapat menimbulkan genangan dalam durasi waktu yang lama sehingga menyediakan habitat yang potensial bagi perkembangbiakan nyamuk. Adapun curah hujan yang tinggi dapat menyebabkan limpasan sehingga membilas nyamuk pradewasa, akibatnya populasi vektor dapat berkurang. Dengan demikian, distribusi nyamuk akan terbatasi jika kondisi terlalu kering atau curah hujan terlalu tinggi. Di Lombok Utara, kepadatan vektor malaria ditemukan berkaitan erat dengan curah hujan pada bulan yang bersangkutan dan sebulan sebelumnya. ${ }^{6}$ Demikian hal-nya dengan kepadatan vektor malaria di Sukabumi cenderung lebih tinggi pada musim hujan. ${ }^{7}$

Pengendalian vektor merupakan salah satu upaya penanggulangan penyakit malaria dengan cara memutus mata rantai siklus hidup vektor. Hal ini bisa dilakukan apabila lokasi sebaran habitat vektor telah diketahui. Namun, luasnya wilayah sebaran habitat vektor, yaitu mulai dari daerah pantai hingga dataran tinggi sering menjadi kendala dalam melakukan pengendalian. Di samping itu, terbatasnya tenaga lapangan dari dinas terkait serta kurangnya pengetahuan masyarakat terhadap penyakit malaria menyebabkan pengendalian ti- 
dak efisien. Hal tersebut dapat diatasi melalui observasi dan pemetaan sebaran habitat larva dengan memperhatian faktor lingkungan termasuk curah hujan. Hasil pemetaan dapat menjadi panduan di lapangan untuk menemukan habitat larva pada saat melakukan pengendalian vektor. Sementara itu, curah hujan dapat menjadi panduan pemberian larvasida terhadap habitat positif larva. Pada saat curah hujan tinggi habitat larva akan terbilas sehingga pemberian larvasida tidak efektif, demikian sebaliknya. Oleh karena itu, penelitian ini bertujuan melakukan pemetaan sebaran habitat serta menganalisis pengaruh curah hujan terhadap jumlah habitat positif larva dan mendeskripsikan karakteristik habitat larva nyamuk Anopheles spp di Distrik Heram Kota Jayapura.

\section{BAHAN DAN METODE}

Penelitian ini berlangsung selama satu tahun dari bulan Juni 2014-Mei 2015 di Distrik Heram Kota Jayapura Propvinsi Papua. Metode yang digunakan merupakan observasi lapangan dengan pendekatan analisis deskriptif dan statistik. Kegiatan penelitian meliputi pengamatan data iklim, pencidukan sampel larva, pengambilan data karakteristik habitat, penandaan titik kordinat habitat, dokumentasi, rearing larva, identifikasi spesies nyamuk Anopheles spp, pemetaan dan analisis. Alat dan bahan yang digunakan terdiri dari cidukan larva ukuran $350 \mathrm{ml}$, termometer air digital, $\mathrm{pH}$ meter digital, refraktometer, wadah plastik, pipet, meteran, satu set alat rearing larva, satu set alat pinning nyamuk, miskroskop stereo, satu set alat ukur data iklim, GPS, kamera digital, dan peta administrasi Kota Jayapura. Penelitian diawali dengan survei pendahuluan dan pemasangan alat ukur curah hujan. Survei pendahuluan berlangsung selama satu bulan (bulan Juni 2014) untuk memetakan titik-titik genangan perairan yang berpotensi menjadi habitat perindukan nyamuk Anopheles spp. Adapun pengukuran data curah hujan dilakukan setiap hari pada pukul 07.00 selama penelitian berlangsung.

Selanjutnya untuk mengetahui sebaran habitat positif larva, dilakukan pemeriksaan genangan satu kali setiap 10 hari selama 11 bulan. Habitat positif larva adalah genangan yang di dalamnya ditemukan larva nyamuk Anopheles spp. Tahapan berikutnya yaitu melakukan penandaan koordinat geografis, pengukuran data karakteristik habitat larva dan pencidukan sampel larva. Pada tahapan ini, pengambilan data spasial dan karakteristik habitat hanya dilakukan pada habitat yang positif memiliki larva sedangkan habitat yang tidak/belum memiliki larva, pengambilan data akan dilakukan pada pengamatan berikutnya. Pengambilan data titik kordinat geografis dilakukan dengan dua cara, yaitu dengan pencatan manual pada buku survei dan perekaman data secara langsung ke dalam GPS. Karakteristik lingkungan habitat yang diukur terdiri dari luas habitat, kedalaman air, suhu air, $\mathrm{pH}$ air dan salinitas sedangkan dasar habitat, kejernihan air, kondisi aliran air serta jenis vegetasi dan hewan air hanya diamati secara langsung. Jika terdapat tanaman air dan hewan air, diidentifikasi berdasarkan jenisnya.

Pengambilan sampel larva menggunakan cidukan $350 \mathrm{ml}$ pada genangan yang cukup air, sedangkan pada genangan dangkal menggunakan pipet. Larva nyamuk Anopheles spp yang tertangkap dimasukkan ke dalam wadah, kemudian dilabel sesuai dengan jenis habitat dan lokasi penangkapan. Selanjutnya dipelihara hingga menjadi nyamuk dewasa agar mudah diidentifikasi. Identifikasi nyamuk dilakukan di laboratorium entomologi Litbang Biomedis Papua di Dok 2 Kota Jayapura. Nyamuk diidentifikasi dengan bantuan entomolog Litbang Biomedis Papua menggunakan kunci identifikasi dari O'Connor dan Soepanto. Selanjutnya jumlah spesies hasil identifikasi dihitung berdasarkan jenis habitat perindukan.

Tahapan analisis dimulai dengan menghitung curah hujan kumulatif 10 hari (dasarian) dan jumlah habitat positif larva berdasarkan jenis habitat. Selanjutnya dilakukan uji statistik fisher exact pada tingkat kepercayaan $95 \%(\alpha=0.05)$ untuk mengetahui signifikansi hubungan antara curah hujan dasarian dengan jumlah habitat positif larva. Jika signifikan, dianalisis lebih lanjut menggunakan regresi linear sederhana. Besarnya pengaruh curah hujan terhadap jumlah habitat positif larva ditentukan berdasarkan nilai koefisien determinan yang dihasilkan oleh regresi linear. Tahapan berikutnya membuat peta spasial sebaran habitat positif larva berdasarkan data pengamatan 10 harian. Pembuatan peta dilakukan menggunakan software arcGIS dan quantumGIS. Agar lebih efisien, peta spasial sebaran habitat positif 
Tabel 1. Curah Hujan Dasarian dan Jumlah Habitat Positif Larva Nyamuk Anopheles spp

\begin{tabular}{|c|c|c|c|c|c|c|c|c|}
\hline \multirow{2}{*}{$\begin{array}{c}\text { Waktu } \\
\text { Pengamatan }\end{array}$} & \multirow{2}{*}{$\begin{array}{c}\text { Curah Hujan } \\
\text { Dasarian } \\
\text { (mm) }\end{array}$} & \multicolumn{6}{|c|}{ Jenis Habitat Positif Larva } & \multirow{2}{*}{$\begin{array}{c}\text { Jumlah } \\
\text { Habita } \\
\text { Positif } \\
\text { Larva }\end{array}$} \\
\hline & & Kobakan & Kubangan & Parit & Kali & Kolam & $\begin{array}{c}\text { Bekas } \\
\text { Tapak Ban }\end{array}$ & \\
\hline $10 \mathrm{Juli}$ & 74.1 & 19 & 13 & 7 & 0 & 9 & 1 & 49 \\
\hline $20 \mathrm{Juli}$ & 79.3 & 19 & 14 & 5 & 0 & 9 & 1 & 48 \\
\hline 30 Juli & 57.66 & 12 & 12 & 12 & 0 & 9 & 2 & 47 \\
\hline 09 Agustus & 4.3 & 0 & 10 & 0 & 7 & 9 & 0 & 26 \\
\hline 19 Agustus & 63.7 & 12 & 14 & 9 & 0 & 9 & 1 & 45 \\
\hline 29 Agustus & 31.7 & 10 & 10 & 10 & 0 & 9 & 2 & 41 \\
\hline 08 September & 237 & 24 & 13 & 0 & 0 & 5 & 0 & 42 \\
\hline 18 September & 90.9 & 22 & 13 & 0 & 0 & 9 & 1 & 45 \\
\hline 28 September & 73.6 & 12 & 14 & 8 & 0 & 9 & 1 & 44 \\
\hline 08 Oktober & 22.1 & 8 & 10 & 8 & 4 & 9 & 0 & 39 \\
\hline 18 Oktober & 17.6 & 0 & 10 & 10 & 4 & 9 & 0 & 33 \\
\hline 28 Oktober & 67.3 & 14 & 14 & 8 & 0 & 9 & 2 & 47 \\
\hline 07 Nopember & 34.2 & 11 & 10 & 9 & 0 & 9 & 1 & 40 \\
\hline 17 Nopember & 184 & 28 & 18 & 0 & 0 & 9 & 0 & 55 \\
\hline 27 Nopember & 51.6 & 12 & 12 & 12 & 0 & 9 & 1 & 46 \\
\hline 07 Desember & 197.5 & 24 & 18 & 0 & 0 & 7 & 0 & 49 \\
\hline 17 Desember & 143.2 & 28 & 19 & 0 & 0 & 9 & 0 & 56 \\
\hline 27 Desember & 77.6 & 18 & 12 & 6 & 0 & 7 & 1 & 44 \\
\hline 06 Januari & 210.2 & 26 & 13 & 0 & 0 & 6 & 0 & 45 \\
\hline 16 Januari & 29 & 10 & 10 & 8 & 0 & 9 & 2 & 39 \\
\hline 26 Januari & 57 & 13 & 13 & 11 & 0 & 7 & 2 & 46 \\
\hline 05 Februari & 128.4 & 26 & 19 & 0 & 0 & 9 & 0 & 54 \\
\hline 15 Februari & 75.1 & 13 & 13 & 7 & 0 & 7 & 1 & 41 \\
\hline 25 Februari & 83.2 & 22 & 14 & 4 & 0 & 8 & 1 & 49 \\
\hline 07 Maret & 211.5 & 28 & 13 & 0 & 0 & 9 & 0 & 50 \\
\hline 17 Maret & 15.6 & 7 & 10 & 9 & 0 & 9 & 0 & 35 \\
\hline 27 Maret & 5.8 & 0 & 10 & 0 & 7 & 9 & 0 & 26 \\
\hline 06 April & 78.2 & 20 & 13 & 8 & 0 & 9 & 1 & 51 \\
\hline 16 April & 19.2 & 8 & 10 & 8 & 3 & 9 & 0 & 38 \\
\hline 26 April & 39.3 & 8 & 11 & 11 & 0 & 9 & 2 & 41 \\
\hline $06 \mathrm{Mei}$ & 48.2 & 10 & 12 & 12 & 0 & 9 & 2 & 45 \\
\hline $16 \mathrm{Mei}$ & 5.4 & 0 & 10 & 0 & 7 & 9 & 0 & 26 \\
\hline $26 \mathrm{Mei}$ & 29 & 6 & 10 & 10 & 0 & 9 & 2 & 37 \\
\hline
\end{tabular}

Sumber : Data primer, 2015

larva per pengamatan ditumpangtindikan (overlay) sehingga menghasilkan satu peta sebaran spasial habitat positif larva nyamuk Anopheles spp di Distrik Heram. Tahap akhir dari penelitian ini yaitu melakukan analisis deskriptif distribusi spasial dan karakteristik habiat perindukan nyamuk Anopheles spp.

\section{HASIL}

Distrik Heram memiliki luas wilayah 63.2 $\mathrm{km}^{2}$ yang terbagi dalam 3 kelurahan dan $2 \mathrm{kam}-$ pung, yaitu Kelurahan Waena, Kelurahan Yaban- sai, Kelurahan Hedam, Kampung Waena dan Kampung Yoka. Sebagian besar wilayah Distrik Heram merupakan perbukitan dan hutan yang tidak dihuni. Curah hujan yang terukur di lokasi pengamatan sejak bulan Juni 2014 hingga Mei 2015 bervariasi antara 4.3 hingga $237 \mathrm{~mm} /$ dasarian atau 105 hingga $439 \mathrm{~mm} /$ bulan. Akumulasi jumlah curah hujan tertinggi terjadi pada bulan Desember 2014 dan terendah pada bulan Agustus 2014. Jumlah hari hujan sepanjang periode pengamatan sebanyak 193 hari dengan rata-rata 16 hari hujan per bulan. Hari hujan paling banyak pada bulan 
Tabel 2. Hasil Uji Statistik Fisher Exact, Korelasi dan Koefisien Determinan antara Curah Hujan dengan Jumlah Habitat Positif Larva

\begin{tabular}{lccc}
\hline \multirow{2}{*}{ Jenis Habitat } & \multicolumn{3}{c}{ Curah Hujan Dasarian } \\
\cline { 2 - 4 } & p value & r & $\mathbf{r}^{\mathbf{2}}$ \\
\hline Kobakan & 0,000 & 0.87 & 0.77 \\
Kubangan & 0,000 & 0.69 & 0.47 \\
Kolam & 0,000 & 0.57 & 0.33 \\
Kali & 0,007 & 0.46 & 0.21 \\
Parit & 0,000 & 0.57 & 0.33 \\
Bekas tapak ban & 0,047 & 0.34 & 0.11 \\
\hline
\end{tabular}

Sumber : Data primer, 2015

Februari 2015 yaitu 19 hari hujan dan paling sedikit pada bulan Oktober 2014 yaitu 12 hari hujan. Variasi intensitas curah hujan dan hari hujan yang terjadi selama periode pengamatan mempengaruhi jumlah dan sebaran habitat larva nyamuk Anopheles spp. Curah hujan yang tinggi dapat menambah jumlah titik genangan air sehingga berpotensi menjadi habitat baru bagi perkembangabiakan nyamuk Anopheles spp. Namun, pada saat yang bersamaan sebagian genangan mengalami limpasan sehingga membilas larva nyamuk. Oleh karena itu, jumlah habitat positif larva nyamuk Anopheles spp yang ditemukan pada saat melakukan pengamatan tidak selalu berbanding lurus dengan banyaknya titik genangan air.

Jumlah genangan air sebagai habitat potensial tempat perkembangbiakan larva nyamuk Anopheles spp di Distrik Heram sebanyak 85 titik genangan yang terdiri dari kobakan $(30,5 \%)$, kubangan (20\%), parit $(28.2 \%)$, kolam $(10.5 \%)$, kali $(8.23 \%)$ dan bekas tapak ban (2.3\%). Genangan air yang positif larva selalu bervariasi mengikuti jumlah curah hujan dasarian, yaitu berkisar antara 26-56 habitat (Tabel 1). Hasil uji statistik fisher exact pada tingkat kepercayaan 95\% $(\alpha=0.05)$ menunjukkan bahwa curah hujan kumulatif 10 harian berpengaruh signifikan terhadap keberadaan larva nyamuk Anopheles spp pada 6 jenis habitat larva, yaitu kubangan ( $\mathrm{p}=0.000)$, kobakan $(\mathrm{p}=0,000)$, parit $(\mathrm{p}=0,000)$, tapak ban $(\mathrm{p}=0,047)$, kolam $(\mathrm{p}=0.000)$ dan kali $(\mathrm{p}=0,007)$ dengan korelasi pearson berkisar antara 0.34 hingga 0.87 . Besarnya pengaruh curah hujan terhadap keberadaan larva pada keenam habit tersebut sebesar 11\% hingga 77\% (Tabel 2).

Keenam jenis habitat larva nyamuk Anopheles spp di Distrik Heram tersebar pada dua kelurahan, yaitu di Kelurahan Waena sebanyak 34

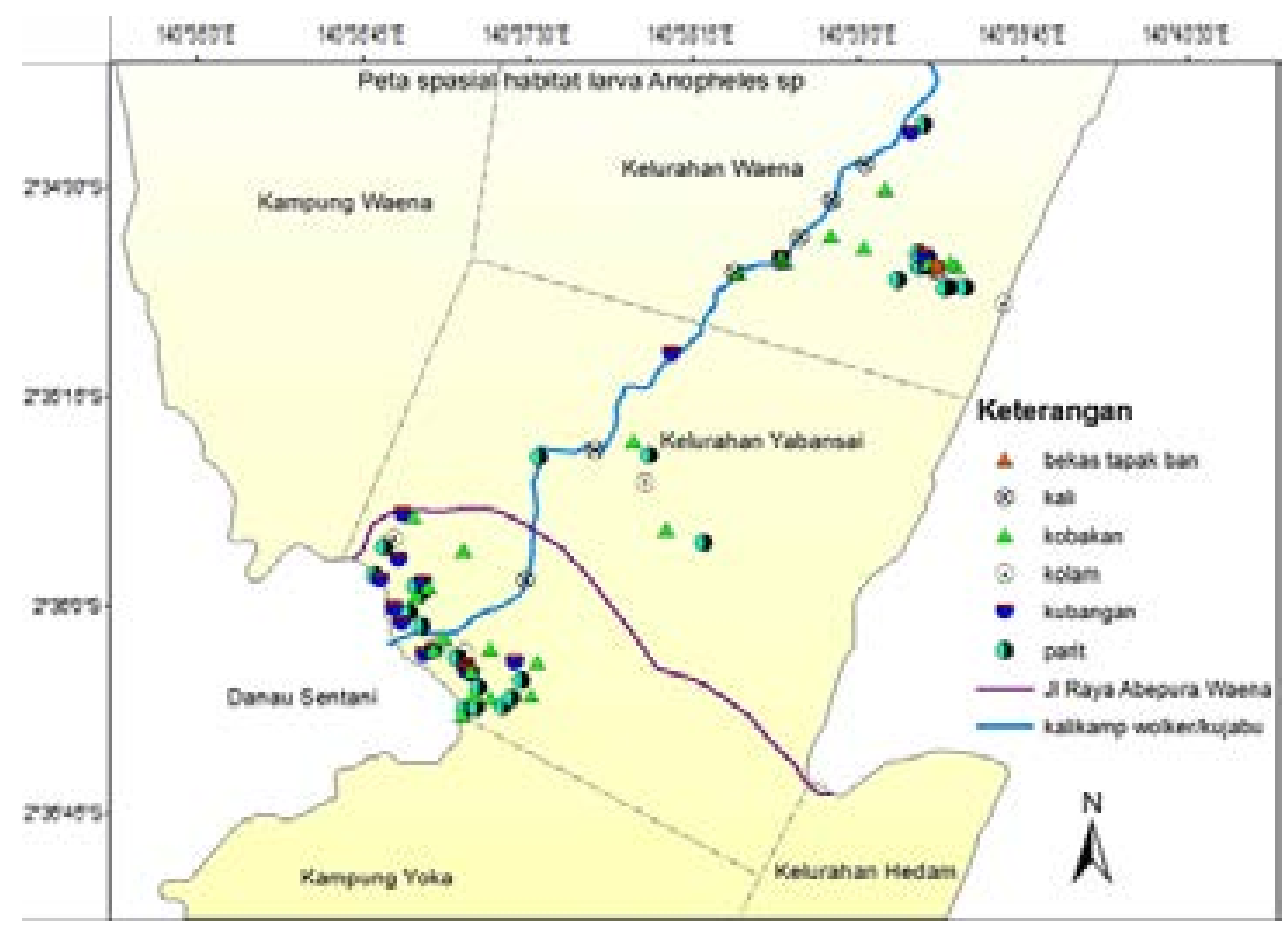

Gambar 1. Peta Overlay Distribusi Spasial Habitat Larva Nyamuk Anopheles spp di Distrik Heram Berdasarkan Curah Hujan Dasarian 
Tabel 3. Wilayah Sebaran Habitat dan Jenis Larva Nyamuk Anopheles spp

\begin{tabular}{|c|c|c|c|c|c|}
\hline \multicolumn{2}{|c|}{ Wilayah sebaran } & \multirow{3}{*}{$\begin{array}{l}\text { Jenis Habitat } \\
\text { Kolam }\end{array}$} & \multirow{3}{*}{$\begin{array}{c}\text { Jumlah Habitat } \\
5\end{array}$} & \multirow{3}{*}{$\begin{array}{c}\begin{array}{c}\text { Jarak Rumah } \\
\text { ke Habitat (m) }\end{array} \\
200\end{array}$} & \multirow{3}{*}{$\begin{array}{l}\text { Jenis Larva } \\
\text { An. koliensis } \\
\text { An. farauti }\end{array}$} \\
\hline Kelurahan & Kampus Uncen & & & & \\
\hline Waena & & & & & \\
\hline & & Kubangan & 3 & 200 & $\begin{array}{l}\text { An. farauti } \\
\text { An. koliensis }\end{array}$ \\
\hline & & Kobakan & 5 & 150 & An. farauti \\
\hline & & Parit & 7 & 150 & An. farauti \\
\hline & & Tapak ban & 2 & 200 & An. farauti \\
\hline & Kamwolker & Kubangan & 2 & 10 & An. farauti \\
\hline & & Kobakan & 4 & 50 & $\begin{array}{l}\text { An. farauti } \\
\text { An. punctulatus }\end{array}$ \\
\hline & & Parit & 1 & 20 & An. farauti \\
\hline & & Kali & 5 & 15 & $\begin{array}{l}\text { An. farauti } \\
\text { An. punctulatus }\end{array}$ \\
\hline \multirow{11}{*}{$\begin{array}{l}\text { Kelurahan } \\
\text { Yabansai }\end{array}$} & Pingir Danau & Kobakan & 14 & 15 & An. farauti \\
\hline & Senatani & & & & An. punctulatus \\
\hline & & Parit & 13 & 10 & $\begin{array}{l}\text { An. farauti } \\
\text { An. punctulatus }\end{array}$ \\
\hline & & Kali & 1 & 25 & An. farauti \\
\hline & & Kolam & 3 & 40 & An. farauti \\
\hline & & Kubangan & 12 & & An. farauti \\
\hline & Sekitar Kali Kujabu & Kobakan & 2 & 15 & An. farauti \\
\hline & & Kubangan & 1 & 15 & An. farauti \\
\hline & & Parit & 3 & 20 & $\begin{array}{l}\text { An. farauti } \\
\text { An. punctulatus }\end{array}$ \\
\hline & & Kolam & 1 & & An. farauti \\
\hline & & Kali & 1 & 35 & An. farauti \\
\hline
\end{tabular}

Sumber : Data primer, 2015

habitat dan di Kelurahan Yabansai sebanyak 51 habitat (Gambar 1). Di Kelurahan Waena, terdapat habitat kobakan (26,5\%), kubangan $(14,7 \%)$, parit $(23,5 \%)$, kolam $(14,7 \%)$, bekas tapak ban $(5,8 \%)$ dan kali $(14,7 \%)$. Sebaran habitat di Kelurahan Waena ditemukan di sekitar Universitas Cende-rawasih pada ketinggian 177-252 meter dari permukaan laut (mdpl) dan di sekitar pinggir Kali Kojubu Kamwolker pada ketinggian 95-134 mdpl. Di Universitas Cenderawasih terdapat 22 habitat potensial yang terdiri dari 5 jenis habitat yaitu kobakan $(22,7 \%)$, bekas tapak ban $(9,1 \%)$, kuba- ngan $(13,6 \%)$, parit $(31,8 \%)$ dan kolam (22,7\%). Sementara di Kampwolker terdapat 12 habitat potensial yang terdiri dari 4 jenis habitat, yaitu kubangan sebanyak $16,6 \%$, kobakan $33,3 \%$, kali $41,6 \%$ dan parit $8,3 \%$. Jarak rumah terdekat ke habitat larva yang ada di Universitas Cenderawasih sekitar $200 \mathrm{~m}$, sedangkan di Kamwolker berjarak sekitar $25 \mathrm{~m}$ (Tabel 3).
Selanjutnya di Kelurahan Yabansai, habitat larva nyamuk Anopheles spp ditemukan di sekitar Kali Kujabu sebanyak 8 habitat pada ketinggian 91-96 mdpl dan pinggir Danau Sentani sebanyak 43 habitat pada ketinggian $76-82$ mdpl. Habitat larva yang terdapat di sekitar Kali Kujabu terdiri dari kobakan $(25 \%)$, kubangan $(12,5 \%)$, parit $(37,5 \%)$, kolam $(12,5 \%)$ dan kali $(12,5 \%)$. Jenis genangan yang sama juga ditemukan disekitar pinggir Danau Sentani, yaitu kobakan $(32,5 \%)$, kubangan $(27,9 \%)$, parit $(30,2 \%)$, kolam $(6,9 \%)$ dan kali (2,3\%). Jarak rumah terdekat ke habitat larva di sekitar Kali Kujabu Kelurahan Yabansai berjarak $55 \mathrm{~m}$ sedangkan di pinggir Danau Sentani berjarak sekitar $35 \mathrm{~m}$ (Tabel 3).

Berdasarkan hasil identifikasi nyamuk dewasa, diketahui bahwa ada tiga jenis spesies larva nyamuk Anopheles spp yang hidup pada keenam habitat di Distrik Heram, yaitu larva Anopheles farauti, punctulatus dan koliensis. Ketiga jenis 


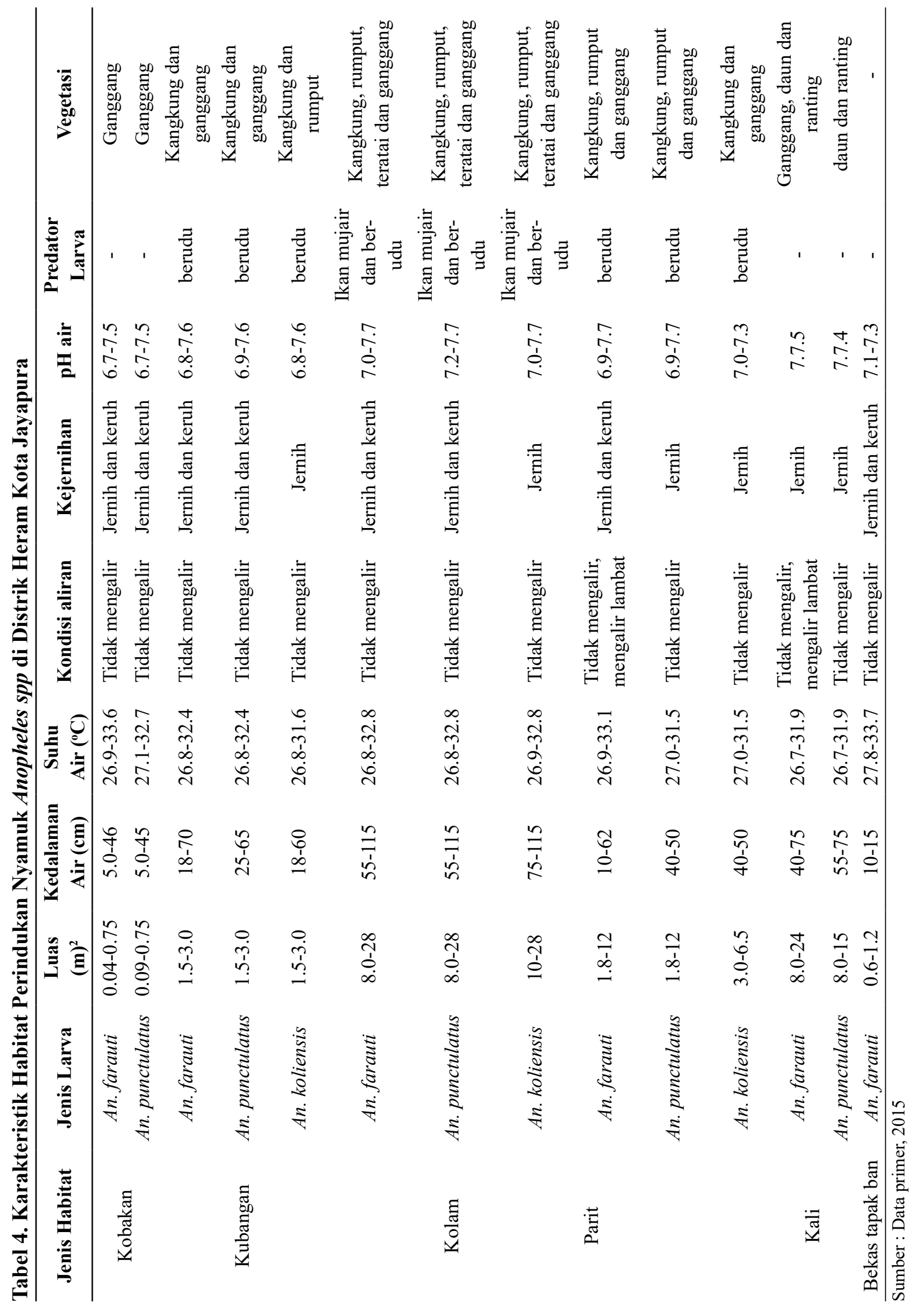


larva tersebut sering ditemukan berada pada satu habitat yang sama. Larva Anopheles farauti merupakan jenis larva yang mempunyai sebaran habitat paling banyak, yaitu $78,8 \%$ dari 85 habiat, kemudian larva Anopheles punctulatus sebanyak $56.4 \%$ dan paling sedikit larva Anopheles koliensis, yaitu 10.6\% (Tabel 3).

Karakteristik habitat larva nyamuk Anopheles spp di Distrik Heram cukup bervariasi. Larva nyamuk Anopheles spp ditemukan pada perairan yang bervegetasi maupun tanpa vegetasi, pada air jernih maupun keruh dan pada air yang tidak mengalir maupun mengalir lambat. Hasil pengukuran karakteristik fisik menunjukkan luas habitat larva berkisar antara 0,04-28 $\mathrm{m}^{2}$ dengan kedalaman air antara 5-115 cm dan kisaran suhu air antara 26,7$33,7^{\circ} \mathrm{C}$. Suhu air paling rendah terukur pada habitat kali dan paling tinggi pada kobakan. Berdasarkan ukuran luas dan kedalaman habitat, kobakan merupakan habitat yang paling kecil dan paling dangkal. Luas kobakan berkisar antara 0.04-0.75 $\mathrm{m}^{2}$ dengan kedalaman antara $5-46 \mathrm{~cm}$ dan suhu air berkisar antara 26.9-33.6 ${ }^{\circ} \mathrm{C}$. Adapun habitat larva yang berukuran paling luas yaitu kolam dengan luas antara 8-28 $\mathrm{m}^{2}$, kedalaman air antara 55-115 cm dan suhu air berkisar anatara 26.8-32.8 ${ }^{\circ} \mathrm{C}$. Seperti hal-nya karakteristik fisik, karakteristik kimia air habitat larva di Distrik Heram juga bervariasi. Namun, variasinya hanya terukur pada satu parameter, yaitu $\mathrm{pH}$ air yang berkisar antara 6,7-7,7, sedangkan salinitas air bernilai 0 karena perairan yang ada di wilayah ini merupakan perairan tawar. Adapun jenis vegetasi yang terdapat di dalam habitat larva yaitu tanaman kangkung, rumput, teratai dan ganggang, sedangkan hewan air yaitu ikan mujair, dan berudu (Tabel 4).

Selain curah hujan, keberadaan larva nyamuk Anopheles spp pada habitat di Distrik Heram juga dipengaruhi oleh karakteristik dan jenis habitat. Umumnya larva Anopheles farauti lebih toleran terhadap lingkungan habitat dibandingkan dengan larva Anopheles punctulatus dan koliensis. Kedalaman habitat larva Anopheles farauti berkisar antara $5-115 \mathrm{~cm}$ dengan suhu air antara 26.7-33.7 ${ }^{\circ} \mathrm{C}$, sedangkan $\mathrm{pH}$ air yang mendukung kehidupan larva ini berkisar antara 6.7-7.7 (Tabel 4). Dalam hal yang sama, larva Anopheles punctulatus juga memiliki sebaran habitat yang cukup luas. Walau demikian, larva ini tidak ditemukan pada air yang mengalir. Kedalam habitat larva Anopheles punctulatus berkisar antara $5-115 \mathrm{~cm}$ dengan suhu air antara 26.7-33.1 ${ }^{\circ} \mathrm{C}$. Ada 5 jenis perairan di Distrik Heram yang menjadi habitat larva Anopheles punctulatus, yaitu kobakan pada kedalaman 5-45 cm dengan suhu air 27.1-32.7 ${ }^{\circ} \mathrm{C}$, kubangan pada kedalaman $25-65 \mathrm{~cm}$ dengan suhu air 26.8-32.4 ${ }^{\circ} \mathrm{C}$, kali pada kedalaman 40-75 $\mathrm{cm}$ dengan suhu air $26.7-31.9^{\circ} \mathrm{C}$, kolam dengan kedalaman 55-115 cm dengan suhun air 26.8-32.8 dan parit pada kedalaman 10-62 cm dengan suhu air 26.9-33.1. Berbeda dengan larva Anopheles farauti dan punctulatus, sebaran habitat perindukan nyamuk Anopheles koliensis di Distrik Heram terbatas pada beberapa jenis habitat saja. Larva ini hanya ditemukan pada air tidak mengalir yang bervegetasi dengan $\mathrm{pH}$ air antara 6.8-7.7. Luas habitat larva Anopheles koliensis berkisar antara $1.5-28 \mathrm{~m}^{2}$ dengan kedalaman air antara $18-115 \mathrm{~cm}$ dan suhu air pada kisaran 26.8-32.8 ${ }^{\circ} \mathrm{C}$ (Tabel 4).

\section{PEMBAHASAN}

Salah satu unsur iklim yang penting dalam mendukung perkembangbiakan nyamuk Anopheles spp adalah curah hujan. Fluktuasi intensitas curah hujan berdampak pada jumlah habitat dan volume genangan air sehingga berpengaruh langsung terhadap keberadaan nyamuk pradewasa pada habitat akuatik. Intensitas curah hujan yang tinggi dapat membilas larva nyamuk sehingga mengurangi habitat positif larva dan kepadatan larva pada saat itu juga. Namun, beberapa hari kemudian akan mucul genangan baru yang potensial bagi perindukan nyamuk. Apabila jumlah curah hujan mencukupi, larva dapat menyelesaikan siklus menjadi nyamuk dewasa. Dengan demikian, secara tidak langsung curah hujan berpengaruh terhadap populasi nyamuk Anopheles spp dewasa sebagai vektor malaria. Akumulasi curah hujan dasarian optimum yang mendukung ketersediaan larva nyamuk Anopheles spp pada habitat akuatik di Distrik Heram bekisar antara 50 $\mathrm{mm}-100 \mathrm{~mm}$ atau rata-rata $5 \mathrm{~mm}-10 \mathrm{~mm} / \mathrm{hari}$. Hal ini agak berbeda dengan penelitian Martens, et al., yang menyatakan bahwa curah hujan minimum yang dibutuhkan oleh nyamuk untuk berkembang adalah $1,5 \mathrm{~mm} /$ hari. ${ }^{8}$ Perbedaan ini disebabkan oleh kondisi fisik lingkungan dan faktor lokal suatu wilayah. Habitat semi permanen di Distrik 
Heram sebagian besar berada pada lahan terbuka sehingga lebih cepat mengalami kekeringan karena laju evaporasinya lebih tinggi. Walau demikian, masing-masing tipe habitat memiliki respon yang berbeda terhadap jumlah curah hujan.

Pada umumnya habitat semi permanen yang dangkal lebih cepat mengalami kekeringan apabila tidak terjadi hujan dan lebih sering mengalami limpasan meskipun curah hujan lebih rendah dari $10 \mathrm{~mm} /$ hari. Keberadaan larva nyamuk Anopheles spp pada habitat kobakan, parit, bekas tapak ban, kali dan sebagian kubangan dangkal langsung dipengaruhi oleh curah hujan pada hari pengamatan hingga 4 hari sebelum pengamatan. Apabila terjadi curah hujan tinggi pada saat itu, maka larva nyamuk sangat jarang ditemukan pada kelima habitat tersebut. Selang beberapa hari kemudian ketika curah hujan kembali rendah, sebagian habitat yang sebelumnya terbilas air hujan menjadi potensial dan positif memiliki larva karena masih memiliki genangan air yang cukup, misalnya cekungan pada kali, parit dan kubangan. Ketiga jenis habitat ini positif memilki larva pada saat terjadi hujan dengan intensitas rendah maupun tidak terjadi hujan dalam 10 hari berturut-turut, tetapi negatif larva ketika terjadi curah hujan tinggi. Sementara habitat jenis kobakan, tapak ban dan kubangan yang dangkal akan mengalami kekeringan pada saat tidak terjadi hujan selama 10 hari berturut-turut. Hal ini akan terus berulang hingga periode pengamatan berikutnya. Oleh karena itu, peluang larva nyamuk untuk berkembang menyelesaikan siklus menjadi nyamuk dewasa pada habitat semi permanen sangat tergantung pada kondisi curah hujan.

Berbeda dengan habitat semi permanen, habitat permanen selalu memiliki genangan air sehingga memungkinkan nyamuk dapat bertelur setiap saat hingga menyelesaikan siklus menjadi nyamuk dewasa, misalnya pada habitat kolam dan kubangan yang dalam. Walau demikian, habitat ini kadang-kadang mengalami limpasan ketika terjadi curah hujan tinggi yang melebihi daya tampung habitat. Kondisi demikian dapat membilas telur maupun larva nyamuk sehingga mempengaruhi keberadaan dan kepadatan larva. Hal ini senada dengan pernyataan Mardiana dan Perwitasari, bahwa curah hujan yang tinggi dapat mempengaruhi habitat sehingga nyamuk tidak dapat berkembang- biak dengan sempurna. ${ }^{9}$ Demikian halnya dengan penelitian Kumar, et al., yang mengungkapkan bahwa pada kondisi tertentu jumlah curah dapat mempengaruhi keberadaan dan kepadatan larva nyamuk Anopheles pada habitat permanen dan semi permanen. ${ }^{10}$

Jumlah habitat positif larva yang ditemukan di Distrik Heram merupakan salah satu penyebab masih tingginya kejadian malaria di wilayah tersebut. Wibowo, juga menyatakan bahwa daerah endemik yang dekat dengan genangan air menjadi penyebab kejadian penyakit malaria. ${ }^{11}$ Ketersediaan habitat perindukan potensial dapat meningkatkan jumlah populasi nyamuk dewasa karena didukung oleh lingkungan habitat akuatik dan kondisi iklim lokal terutama curah hujan. Umumnya peningkatan penularan penyakit malaria berkorelasi langsung dengan kepadatan nyamuk dewasa. Semakin tinggi kepadatan nyamuk Anopheles yang infektif, maka penularan penyakit malaria juga akan meningkat. Penelitian Suwito et al., membuktikan bahwa jumlah kasus malaria sebulan mendatang 46,4\% disebabkan oleh kepadatan Anopheles pada bulan sekarang. ${ }^{12}$ Hal yang sama juga dikemukakan oleh Mardiana dan Munif, yang menyatakan bahwa kepadatan Anopheles An. aconitus di Purworejo mempunyai hubungan positif dengan insiden malaria. ${ }^{13}$

Karakteristik habitat perindukan nyamuk di Distriki Heram turut mempengaruhi keberadaan larva pada habitat akuatik. Umumnya nyamuk Anopheles spp bertelur pada semua genangan air dengan dasar lumpur atau pasir maupun campuran keduanya tanpa membedakan ukuran luas. Meskipun luas perairan tidak membatasi nyamuk Anopheles spp dalam meletakkan telurnya, tetapi konfirmasi luasan diperlukan untuk perencanaan pengendalian dan pemberantasan nyamuk yang lebih efektif. Adapun karakteristik fisik habitat misalnya suhu air, kedalaman air, kekeruhan air dan kecepatan aliran air merupakan faktor yang dapat membatasi keberadaan larva nyamuk Anopheles spp pada habitat akuatik. Setiap spesies larva memiliki kemampuan adaptasi yang berbeda terhadap faktor-faktor tersebut. Di dalam habitat dangkal tanpa vegetasi, larva ditemukan berlindung di dasar habitat. Genangan air yang dangkal memungkin larva dapat bertahan lebih lama di dasar habitat sebelum muncul ke permukaan untuk 
mengambil oksigen. Selanjutnya pada habitat yang dalam, larva nyamuk Anopheles spp hanya ditemukan pada pinggir habitat dan bagian habitat yang memiliki vegetasi air.

Tingkat kedalaman air yang terukur pada habitat perindukan nyamuk Anopheles spp selalu berubah berdasarkan jumlah curah hujan, hari hujan dan tipe habitat. Oleh karena itu, hasil pengukuran kedalaman air pada penelitian ini merupakan kedalaman relatif habitat larva nyamuk Anopheles spp, seperti hal-nya kedalaman air, kecepatan aliran air dan tingkat kekeruhan juga membatasi keberadaan larva di dalam habitat akuatik. Larva nyamuk Anopheles spp lebih sering ditemukan pada air yang tidak mengalir, meskipun ada spesies tertentu yang ditemukan pada air mengalir lambat yang bervegetasi, misalnya pada pinggir parit. Dalam hal ini, vegetasi berfungsi sebagai penghambat laju aliran air sekaligus tempat larva berlindung. Berdasarkan kekeruhan air, larva nyamuk Anopheles spp lebih sering ditemukan pada air jernih meskipun ada juga yang ditemukan pada air keruh hingga batas kekeruhan tertentu. Suspensi di dalam air yang sangat keruh tidak dapat ditoleransi oleh larva karena dapat mengganggu alat pernapasan, akibatnya larva nyamuk banyak yang mati.

Faktor lingkungan fisik lainnya yang menjadi pembatas keberadaan larva nyamuk Anopheles spp dalam perairan yaitu suhu air. Variasi suhu air dipengaruhi oleh beberpa faktor, diantaranya letak geografis, radiasi matahari, suhu udara, kedalam air dan vegetasi yang ada disekitarnya. Pada umumnya suhu air lebih tinggi pada genangan air dangkal yang terpapar sinar matahari langsung. Sebaliknya pada genangan air yang dalam, suhu air cenderung lebih rendah. Selain sebagai faktor pembatas keberadaan larva di dalam perairan, suhu air juga mempengaruhi tahap perkembangan nyamuk pradewasa. Suhu air yang rendah akan memperlambat tahap perkembangan nyamuk pradewasa, sedangkan suhu tinggi pada batas tertentu dapat mempercepat tahap perkembangan. Suhu air yang terukur di lokasi penelitian merupakan kisaran suhu yang masih dapat mendukung perkembangan nyamuk pradewasa. Menurut Goswami, et al., suhu air $16^{\circ} \mathrm{C}$ merupakan suhu yang paling rendah dibutuhkan larva nyamuk untuk berkembang sedangkan suhu $36^{\circ} \mathrm{C}$ selama 2 bulan berturut-turut dapat mematikan semua larva nyamuk. ${ }^{14}$ Penelitian di laboratorium yang dilakukan oleh Bayoh, menunjukkan bahwa larva an. gambiae dapat berkembang menjadi nyamuk dewasa dalam waktu 10 hingga 38 hari pada suhu air yang konstan $18^{\circ} \mathrm{C}-34^{\circ} \mathrm{C} .{ }^{15}$ Selanjutnya di Kenya Paaijmans, et al., menemukan larva nyamuk Anopheles masih dapat berkembang optimal pada suhu air yang lebih tinggi $4-6^{\circ} \mathrm{C}$ dari suhu air ratarata harian. ${ }^{16}$

Seperti halnya dengan suhu air, derajat keasaman $(\mathrm{pH})$ merupakan unsur kimia air yang menjadi faktor pembatas keberadaan larva nyamuk Anopheles spp di dalam perairan. Hal ini disebabkan tiap spesies larva nyamuk memiliki toleransi yang berbeda terhadap nilai $\mathrm{pH}$ air. Ada spesies tertentu yang dapat hidup pada $\mathrm{pH}$ air yang rendah dan ada juga yang bisa bertahan hidup pada $\mathrm{pH}$ air yang tinggi. Misalnya di Lampung Selatan, $\mathrm{Pa}-$ ngastuti et al., menemukan larva nyamuk Anopheles spp dapat hidup pada $\mathrm{pH} 9.33 .{ }^{17}$ Mengacu pada nilai $\mathrm{pH}$, tingkat keasaman air yang terukur di Distrik Heram merupakan $\mathrm{pH}$ normal yang dapat mendukung kehidupan organisme akuatik termasuk larva nyamuk Anopheles spp. Menurut Sandy, larva nyamauk Anopheles farauti punctulatus dan koliensi di Papua dapat hidup pada $\mathrm{pH}$ air antara $6-8 .^{18}$

Selain karakteristik fisik dan kimia air, karakteristik biologi air juga berperan penting dalam mentukan keberadaan dan populasi larva nyamuk Anopheles spp pada habitat akuatik. Tanaman air dapat menghalangi sinar matahari dan melindungai larva dari serangan predator. Selain itu, dapat juga menyediakan makanan bagi larva dalam bentuk mikrofauna maupun makrofauna. Larva nyamuk Anopheles spp di Distrik Heram lebih sering ditemukan pada habitat yang memiliki tanaman air dengan kerapatan sedang. Sementara larva pada habitat yang bervegetasi dengan kerapatan tinggi sangat jarang ditemukan. Hal ini diduga, larva nyamuk akan kesulitan mengambil oksigen pada vegetasi air yang sangat rapat. Pada umumnya tanaman air memberikan konstribusi positif bagi keberadaan dan perkembangan larva nyamuk Anopheles spp di dalam habitat akuatik. Hal ini berbeda dengan keberadaan hewan air yang sebagian besar merupakan predator larva nyamuk. Pada umumnya larva nyamuk Anopheles 
spp jarang ditemukan pada habitat yang memiliki hewan air tanpa vegetasi.

Meskipun sebaran habitat perindukan nyamuk Anopheles spp di Distrik Heram hanya ditemukan pada pada 2 kelurahan, tetapi sebagian habitat larva posisinya berdekatatan dengan permukiman yang ada di kelurahan lain. Misalnya di Kelurahan Yabansai, habitat larva nyamuk yang ada di sekitar pinggir Danau Sentani posisinya berdekatan dengan permukiman warga yang ada di Kampung Yoka. Dengan demikian, penularan penyakit malaria tetap terjadi di wilayah yang tidak memiliki habitat perindukan nyamuk. Hal ini didukung oleh jarak terbangnya yang relatif jauh sehingga memungkinkan nyamuk dapat mencari darah ke permukiman yang jauh dari habitatnya. Hasil penelitian Kazwaini dan Martini, menunjukkan bahwa risiko penularan malaria dapat terjadi pada jarak kurang dari $1000 \mathrm{~m} .{ }^{19}$

\section{KESIMPULAN DAN SARAN}

Ada enam jenis habitat larva nyamuk Anopheles spp yang ditemukan di Distrik Heram, yaitu kobakan, kubangan, parit, kali, kolam dan tapak ban. Keenam jenis habitat tersebut tersebar pada dua wilayah perintahan yaitu di Kelurahan Waena sebanyak 34 habitat dan di Kelurahan Yabansai sebanyak 51 habitat. Keberadaan larva pada keenam habitat di Distrik Heram signifikan dipengaruhi oleh curah hujan dasarian sebesar $11 \%$ hingga $77 \%$. Selain curah hujan, karakteristik habitat juga mendukung keberadaan larva nyamuk Anopheles spp pada masing-masing habitat. Ada tiga jenis spesies larva nyamuk Anopheles spp yang hidup pada keenam habitat Distrik Heram, yaitu larva Anopheles farauti, punctulatus dan koliensis. Larva Anopheles farauti merupakan jenis larva yang mempunyai sebaran habitat paling banyak, yaitu 78,8\% dari 85 habiat, kemudian larva Anopheles punctulatus sebanyak $56.4 \%$ dan paling sedikit larva Anopheles koliensis yaitu 10.6\%. Mengingat curah hujan dan karakteristik lingkungan habitat mempengaruhi kelangsungan hidup larva nyamuk Anopheles spp, maka kedua faktor ini perlu dipertimbangkan dalam melakukan pengendalian vektor malaria di Distrik Heram.

\section{DAFTAR PUSTAKA}

1. Arsin, Arsunan. Malaria di Indonesia: Tinjau- an Aspek Epidemiologi. Makassar: Masagena Press; 2012.

2. WHO. World Malaria Report 2016. France : World Health Organization; 2017.

3. Kemekes RI. Profil Data Kesehatan Indonesia Tahun 2016. Jakarta: Kementerian Kesehatan RI; 2017.

4. Dines Kesehatan. Profil Kesehatan Kota Jayapura 2014. Jayapura: Dinas kesehatan; 2015.

5. Zhou, G., Minakawa, N., GithekoA.K., Yan, G. Association between Climate Variability and Malaria Epidemics in the East African Highlands. Proc Natl Acad Sci. 2004;101(8):237580.

6. Hidayati, R., Boer, R., Hadi, U.K., Buono, A., dan Hakim, L. Perubahan Risiko Penyakit Demam Berdarah dan Malaria akibat perubahan Iklim di Indonesia. Jakarta: Kementerian Riset dan Teknolog; 2009.

7. Hakim, L., Ipa, M. Sistem Kewaspadaan Dini KLB Malaria Berdasarkan Curah Hujan, Kepadatan Vektor dan Kesakitan Malaria di Kabupaten Sukabumi. Media Litbang Kesehatan. 2007; XVII(2):34-40.

8. Martens, W. J. M., Jetten, T. H., Rotmans, J., Niessen, L. W. Climate Change and Vector Borne Diseases a Global Modeling Perspective. Human and Policy Dimensions. Global Environmental Change.1995;5(3):195-209.

9. Mardiana, Permatasari, D. Insiden Malaria dan Pola Iklim di Kabupaten Kapuas Propinsi Kalimantan Tengah dan Kabupaten Sumba Barat Propinsi Nusa Tenggara Timur, Indonesia Tahun 2005 - 2009. Jurnal Ekologi Kesehatan. 2014;13(1):59-70.

10. Kumar, B., Singh, N. and Dhiman, R.C. Impact of Rainfall on Larval Density of Malaria vectors in District Baghpat, Uttar Pradesh. Research Journal of Pharmaceutical, Biological and Chemical Sciences. 2017;8(4):664.

11. Wibowo. Risiko Kejadian Malaria di Wilayah Kerja Puskesmas Kecamatan Cikeusik. Media Kesehatan Masyarakat Indonesia. 2017;13(2):139-46.

12. Suwito, Hadi, U.K., Sigit, S.H dan Sukowati, S. Hubungan Iklim, Kepadatan Nyamuk Anopheles dan Kejadian Penyakit Malaria. Jurnal Entomologi Indonesia. 2010;7(1):42- 
53.

13. Mardiana dan Munif, A. Hubungan antara Kepadatan Vektor Anopheles aconitus dan Insiden Malaria di Daerah Endemik di Kabupaten Sukabumi Jawa Barat. Jurnal Ekolologi Kesehatan. 2009;8(1):901-914.

14. Goswami, P., Murty, U. S., Mutheneni, S. R., Kukkuthady, A., \& Krishnan, S. T. A Model of Malaria Epidemiology Involving Weather, Exposure and Transmission Applied to North East India. PLoS One. 2012;7(11).

15. Bayoh, M. N., \& Lindsay, S. W. Temperature Related Duration of Aquatic Stages of the Afrotropical Malaria Vector Mosquito Anopheles Gambiae in the Laboratory. Medical and Veterinary Entomology. 2004;18(2):174-9.

16. Paaijmans, K. P., Imbahale, S. S., Thomas, M. B., \& Takken, W. Relevant Microclimate for
Determining the Development rate of Malaria Mosquitoes and Possible Implications of Climate Change. Malaria Journal. 2010;9(1):196.

17. Pangastuti, R.L., Kurniawan, B., Rosa, E. Characteristic Anopheles sp Larvae Breeding Places in the Village Way Muli Lampung Selatan. Jurnal Majority. 2015;4(1):57-68.

18. Sandy, S. Bionomi Vektor Malaria Kelompok Anopheles punctulatus (Anopheles farauti, Anopheles koliensis, Anopheles punctulatus) di Provinsi Papua. BALABA. 2014;10(1):4752.

19. Kazwaini, M dan Martini, S. Tempat Perindukan Vektor Anopheles dan Pengaruh Jarak Tempat Perindukan Vektor terhadap Kejadian Malaria pada Balita. Jurnal Kesehatan Lingkungan. 2015;2(2):173-83. 